\title{
Performance-Based \\ Budgeting in the Public Sector
}

MICHIEL S. DE VRIES, JURAJ NEMEC and DAVID ŠPAČEK (eds.) Governance and Public Management Series, Palgrave Macmillan, London, 2019, pp. 274

Book review by INA ĎURČEKOVÁ*

https://doi.org/10.3326/pse.44.3.6

\footnotetext{
* Received: January 19, 2020

Accepted: February 4, 2020
}

$\overline{\text { Ina ĎURČEKOVÁ, Ing. }}$

Faculty of Economics, Matej Bel University in Banská Bystrica, Tajovského 10, 97590 Banská Bystrica, Slovakia

e-mail: ina.durcekova@umb.sk ORCID: 0000-0002-3647-2275 
Performance-based budgeting (PBB) has been a crucial part of public sector management in many countries for the past few decades. Different aspects of PBB have been implemented on various levels of government and fields of public policy. The book Performance-Based Budgeting in the Public Sector provides a comprehensive view of how several countries use PBB in public management. One of the assets of this publication with three editors (Michiel S. de Vries, Juraj Nemec and David Špaček $)^{1}$, is its collaboration of diverse economists from various countries and from different fields of study. The case studies are provided not only by researchers from academia but also by professionals with practical public sector experience, municipal councillors or internal auditors, for instance. This collaboration between academic insights and hands-on experience provides an interesting perspective and unique conclusions in the field of PBB. A contributing fact is that the book not only focuses on EU countries (as is common in such publications) but also expands its analysis and conclusions to countries all over the world.

The publication is divided into several sections. Formally, the book has four main parts - introduction, use of PBB in the developed world, use of PBB in transitional countries and conclusion. However, the section on PBB in transitional countries has also a separate part on performance-based funding (PBF). The main distinction within the book can be seen between the first chapter and the rest of the publication - while the first chapter (introduction) focuses on the theoretical aspects of $\mathrm{PBB}$, the others summarize the main findings of various authors concerning $\mathrm{PBB}$ in their respective countries. Most case studies emphasize the process of the implementation and historical development of PBB in the country under review, but several chapters provide analysis of primary or secondary data in order to evaluate the effectiveness and use of PBB and PBF. Case studies vary not only in the data sources used, but also in the level of government they focus on (implementation and use of PBB at national, regional or local levels).

The introduction of the book provides an in-depth, but at the same time easy to understand definition of PBB. It illustrates different types of PBB that can be implemented to best fit the needs of specific areas of the public sector and various government programs. However, the book not only accentuates the benefits PBB may bring, but also compares it to other forms of budgeting and compares and contrasts the advantages and obstacles, and ponders whether it should be implemented or not. Thus, the introduction is more than just a mere collection of theoretical facts and information, it also asks questions and challenges a reader to discuss the pros and cons of PBB.

\footnotetext{
${ }^{1}$ Michiel S. de Vries, professor of the Department of Public Administration and of the Institute of Management Research at Radboud University of Nijmegen, the Netherlands and distinguished professor at Kaunas Technological University; Juraj Nemec, professor of Public Finance and Public Management at Masaryk University in Brno, Czech Republic and at Matej Bel University Banska Bystrica, Slovakia; David Špaček, associate professor at the Faculty of Economics and Administration, Masaryk University in Brno, Czech Republic.
} 
Chapters 2 through 6 focus on the implementation and effectiveness of PBB in some developed countries (US, Australia, Netherlands, Germany, Austria, Switzerland and Italy). A case study introducing PBB in the US analyses the effectiveness of PBB in the field of higher education using secondary data, based on several factors, such as length of time it has been in use, level of higher education institution or state characteristics. A case study from Australia, specifically from New South Wales, emphasizes the risks and undesired effects that performance monitoring might bring if policy makers do not follow the theoretical aspects of performance measurement. Chapters concerning the Netherlands, Germany, Austria, Switzerland and Italy summarize how PBB was implemented in these countries on various levels of centralization.

Chapters 7 through 11 focus on the implementation of PBB in transitional and developing countries (South Africa, Russia, Ukraine, Slovakia and Slovenia). The common characteristics of transitional countries is that they are latecomers in the field of PBB compared to developed countries, having started introducing it in the last decade or two. The case study of Russia shows the PBB implementation process, while chapters dealing with South Africa, Slovenia and Ukraine focus more on the specific projects in one of the regions to provide an in depth understanding of how it is actually used in the selected region and how it is connected to performance measurement. A section dedicated to Slovakia uses primary (questionnaire) and secondary data to analyse budget indicators and to present opinions of municipal representatives on PBB.

Chapters 12 and 13 deal with Bulgaria, Slovakia and the Czech Republic. The focus of the Bulgarian case study is on the funding of kindergartens, concluding that there is no link between funds and the performance of these institutions. The case study of Slovakia and the Czech Republic ponders PBF of universities and how it affects performance, while highlighting the downsides and challenges of such funding.

There are some common themes that can be seen throughout the book. Firstly, some case studies begin with the emphasis on the New Public Management (NPM) movement, which is said to be some sort of starting point for PBB in all the countries under review. While the NPM movement dates back to the 1990s, PBB started being implemented in the last ten to twenty years in most countries showed in the publication. Secondly, some of the presented case studies focus on the historical development of PBB implementation in the country and the obstacles the government faced in its implementation. Whether developed or transitional, most countries are still undergoing the process of transitioning from more traditional (e.g. item-based) budgeting towards PBB.

Even though the publication focuses on several countries that operate in completely different economic conditions, they mostly face the same issues and challenges in terms of PBB. One of the focal points of its implementation is the 
definition and measurement of performance indicators. While focus on performance indicators gradually grows, there are still some problems concerning performance measurement. Since it is sometimes difficult to quantify the performance of policy programs, many programs focus on input or output indicators, instead of outcome or ratio indicators, which are better suited to illustrate the performance of a program. It is also difficult to define and measure policy goals and to link them to indicators - while some policy programs define too few performance indicators, others define too many and fail to keep track of them. The main issue concerning performance measurement is that even though countries adhere to some sort of legislation or standards regarding PBB, most of those presented have weak connections between performance indicators and the actual process of budgeting, meaning that despite defining, measuring and reporting performance indicators, policy makers rarely adjust budget appropriations according to the achieved results. The often used top-down approach in the transition to PBB results in public sector employees without sufficient education, qualification and skills to adhere to these changes. The unclear definition of PBB often leads PBB concepts differing among countries and even on various levels within the country. It is difficult, accordingly, to compare the extent of PBB use in different regions.

The conclusion of the book provides a brief summary of all case studies presented and their main findings, with editors' call for attention to the recurring obstacles of PBB and the statement that these dilemmas need to be taken into account for its further implementation.

Overall, Performance-Based Budgeting in the Public Sector is a publication that provides a comprehensive and eloquent background to PBB that can be used as introduction to the field, as well as a guideline for government officials to the main challenges and opportunities PBB approach provides. The writing style is easy to understand but still manages to adhere to high academic standards. The book also provides future opportunities to expand the scope of research to other countries or to revisit the presented case studies in the future and to document the further progress (or regress) they may have undergone in the field of PBB. 